\title{
CURCUMIN ALLEVIATES LUMBAR RADICULOPATHY BY REDUCING NEUROINFLAMMATION, OXIDATIVE STRESS AND NOCICEPTIVE FACTORS
}

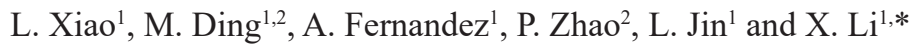

${ }^{1}$ Department of Orthopaedic Surgery, University of Virginia, Cobb Hall, 135 Hospital Dr. Charlottesville, VA 22908, USA

${ }^{2}$ Department of Anaesthesiology, Shengjing Hospital of China Medical University, Shenyang, China

\begin{abstract}
Current non-surgical treatments for lumbar radiculopathy [e.g. epidural steroids and Tumour necrosis factor- $\alpha$ (TNF- $\alpha$ ) antagonists] are neither effective nor safe. As a non-toxic natural product, curcumin possesses an exceptional anti-inflammatory profile. We hypothesised that curcumin alleviates lumbar radiculopathy by attenuating neuroinflammation, oxidative stress and nociceptive factors. In a dorsal root ganglion (DRG) culture, curcumin effectively inhibited TNF- $\boldsymbol{\alpha}$-induced neuroinflammation, in a dose-dependent manner, as shown by mRNA and protein expression of IL-6 and COX-2. Such effects might be mediated via protein kinase B (AKT) and extracellular signal regulated kinase (ERK) pathways. Also, a similar effect in combating TNF- $\alpha$ induced neuroinflammation was observed in isolated primary neurons. In addition, curcumin protected neurons from TNF- $\alpha$-triggered excessive reactive oxygen species (ROS) production and cellular apoptosis and, accordingly, promoted mRNA expression of the anti-oxidative enzymes haem oxygenase-1, catalase and superoxide dismutase-2. Intriguingly, electronic von Frey test suggested that intraperitoneal injection of curcumin significantly abolished ipsilateral hyperalgesia secondary to disc herniation in mice, for up to 2 weeks post-surgery. Such in vivo pain alleviation could be attributed to the suppression, observed in DRG explant culture, of TNF- $\alpha$-elicited neuropeptides, such as substance $\mathrm{P}$ and calcitonin generelated peptide. Surprisingly, micro-computed tomography $(\mu \mathrm{CT})$ data suggested that curcumin treatment could promote disc height recovery following disc herniation. Alcian blue/picrosirius red staining confirmed that systemic curcumin administration promoted regeneration of extracellular matrix proteins, visualised by presence of abundant newly-formed collagen and proteoglycan content in herniated disc. Our study provided pre-clinical evidence for expediting this natural, non-toxic pleiotropic agent to become a new and safe clinical treatment of radiculopathy.
\end{abstract}

Keywords: curcumin, disc herniation, radiculopathy, neuroinflammation, oxidative stress, neuropathic pain, toxicity, nociceptive.
*Address for correspondence:

Dr Xudong Li, MD, PhD

Rm B051, Cobb Hall, Department of Orthopaedic Surgery, University of Virginia

135 Hospital Dr. Charlottesville, VA 22908, USA

Telephone number: +14349824135

Fax number: +1 4349241691

Email: x12n@virginia.edu

\section{Introduction}

A recent investigation suggested that there is an inverse relationship between dietary consumption of antioxidantrich foods and prevalence of human illness (Arulselvan et al., 2016). Therefore, in our opinion, incorporation of antioxidant - anti-inflammatory natural product compounds - either in the daily diet or as supplemental medicine, can be a promising and safe solution to solve human health issues, in particular chronic disorders, once their chemical properties are defined and pharmacological effects are elucidated.

The most recent Global Burden of Disease study identified back and leg pain as the most common cause of disability worldwide, with a prevalence of over $80 \%$ and an estimated annual cost of $\$ 100$ billion per year in the USA (Andersson, 1999; Hoy et al., 2014). Currently, there is no safe and effective therapy available to treat lumbar radiculopathy and discogenic low back pain. At present, epidural injection of steroids is commonly used to attenuate inflammation through inhibition of prostaglandins. However, such treatment has been associated with various unexpected effects such as infection, allergic reaction, malignancy or confounding results (Bhatia et al., 2016) and may affect other important body functions such as development, homeostasis, metabolism and cognition (Biddie et al., 2012). In addition, Tumour necrosis factor- $\alpha$ (TNF- $\alpha$ ) antagonists, such as rituximab, adalimumab, thalidomide and etanercept have been utilised to treat inflammation and TNF- $\alpha$-mediated chronic pain during the onset of inflammation, sensory nerve damage and autoimmune diseases (Feldmann and Maini, 2003; Leung and Cahill, 2010; Mattei et al., 2015). Nevertheless, the safety of these TNF- $\alpha$ antagonists has raised severe concerns in various medical situations (Isyar et al., 2015; Kübra Elçioğlu et al., 2015; Lories and de Vlam, 2014). For this reason, it is an urgent mission for researchers to 
identify a new therapeutic strategy with no or minimal toxicity/adverse effect. Strategically, the identification of a novel therapy from a library of natural products with proved safety profile appears as the most effective approach, due to the increasing pharmaceutical expenditure (Frearson and Wyatt, 2010) and urgent medical need.

Numerous studies have utilised natural products as novel therapeutics for various pathological conditions, including neuropathic pain. For example, puerarin has been identified as a new lead compound to treat spared nerve injury induced depression and pain comorbidity. In mice, it activates extracellular signal regulated kinase (ERK), cAMP response element-binding protein (CREB) and brain-derived neurotrophic factor (BDNF) pathways (Zhao et al., 2016). Similarly, n-3 and n-6 fatty acids have been shown to contribute to the beneficial effects of an intervention (Brenna et al., 2015; Ramsden et al., 2015). Also, anti-nociceptive mediators derived from docosahexaenoic acid (DHA), including D-series resolvins, neuroprotectins, maresins and DHA-epoxides, and antinociceptive mediators derived from eicosapentaenoic acid (EPA), including E-series resolvins and EPA-epoxides, have been shown to have therapeutics effects. Resolvin E1 (RvE1) inhibits transient receptor potential cation channel subfamily V member 1 (TRPV1) activity by activation of the chemerin 23 receptor (ChemR23), an RvE1 receptor located in dorsal root ganglion (DRG) neurons, and therefore exerts an inhibitory effect on inflammatory pain (Jo et al., 2016). Neuroprotectin-1 (NPD1), an anti-inflammatory lipid mediator, has been shown to regulate TRPV1/TNF- $\alpha$-mediated spinal synaptic plasticity, identifying NPD1 as a novel analgesic for treating inflammatory pain (Park et al., 2011).

Curcumin - the golden stone of India - is the yellowcolouring component of the turmeric spice. It has attracted a considerable interest in medicine due to its negligible toxicity and multiple therapeutic effects including anticancer, anti-inflammatory and anti-microbial activities (Rohanizadeh et al., 2016). Based on preclinical and limited clinical trials, curcumin has shown to be a safe and potential therapeutic agent against diseases, such as inflammatory bowel disease, pancreatitis, arthritis and chronic anterior uveitis, as well as certain types of cancers (Kunnumakkara et al., 2008; Rohanizadeh et al., 2016; Shehzad et al., 2011). Studies, covering a treatment period of three months, have shown that curcumin does not possess acute toxicity at doses of $2 \mathrm{~g} / \mathrm{kg}$ of body weight in mice and $8,000 \mathrm{mg} /$ day in humans (Chainani-Wu, 2003; JS, 2009). In addition to its anti-inflammatory effect, curcumin has demonstrated an analgesic effect in several animal models of neuropathic pain, such as pain in diabetes (Meng et al., 2015) and chronic constrictive injury of spinal cord (Jeon et al., 2013; Noorafshan et al., 2011a). Curcumin has been reported to act on multiple cellular targets and signalling pathways suppressing production of mediators of inflammation and neuronal apoptosis, including toll-like receptors and nuclear factor- $\kappa \mathrm{B}$ (Rahimifard et al., 2017), growth factors, inflammatory cytokines and protein kinases (Zhou et al, 2011). In the search for new therapeutics to combat lumbar radiculopathy, curcumin arises as an outstanding agent, given its excellent anti-inflammatory, anti-oxidative and analgesic potentials. Most importantly, the safety profile of curcumin makes it a distinctive therapeutic candidate.

In the current study, we present our preclinical findings supporting curcumin as a potent therapy to treat lumbar radiculopathy. Our in vitro data suggested that curcumin successfully suppressed TNF- $\alpha$-induced neuroinflammation and nociceptive neuropeptides synthesis/release in mouse DRG explant culture, attenuated TNF- $\alpha$-triggered reactive oxygen species (ROS) production and promoted anti-oxidative enzyme production in primary neurons. Intriguingly, in our mouse model, systemic administration of curcumin significantly prohibited hyperalgesia secondary to disc herniation and promoted cell regeneration in herniated discs. This explorative study established a foundation for implementing this natural occurring non-toxic pleiotropic agent as a clinical treatment for radiculopathy.

\section{Materials and Methods}

\section{Isolation of DRG explants and primary neurons}

Animal protocols were approved by the Institutional Animal Care and Use Committee of the University of Virginia. In brief, mice were sacrificed in $\mathrm{CO}_{2}$ chamber followed by cervical dislocation. The bilateral DRGs were immediately collected from the spinal column of Balb/C mice [(male and female, 8-12 weeks, 20-25 g (Envigo, Indianapolis, IN, USA)], following our previously published protocol (Liu et al., 2013), and cultured in F-12 growth medium containing $10 \%$ FBS, $100 \mathrm{U} / \mathrm{mL}$ penicillin, $100 \mu \mathrm{g} / \mathrm{mL}$ streptomycin and $10 \mathrm{ng} / \mathrm{mL}$ nerve growth factors (NGF) (BD Biosciences, San Jose, CA, USA). Cell culture supplies, such as F-12 Nutrient Mixture (Ham), foetal bovine serum (FBS), Dulbecco's phosphatebuffered saline (PBS) and penicillin-streptomycin were purchased from Gibco Invitrogen (Carlsbad, CA, USA). Hank's balanced salt solution (HBSS, free of $\mathrm{Ca}^{2+}$ and $\mathrm{Mg}^{2+}$ ) were purchased from Life Technologies (Grand Island, NY, USA). Other chemicals and solvents were purchased from Sigma-Aldrich (St. Louis, MO, USA) unless specified.

Primary neurons were isolated from freshly harvested DRGs following published protocols with minor modifications (Liu et al., 2013; Malin et al., 2007). Briefly, DRGs (20-30) were digested in $3 \mathrm{~mL}$ papain (40 U/mL, in HBSS) (Worthington Biochemical Corporation, Lakewood, NJ, USA) solution at $37^{\circ} \mathrm{C}$ for $10 \mathrm{~min}$ and centrifuged. The upper solution was replaced with $3 \mathrm{~mL}$ collagenase $(0.2 \%$ in HBSS) (SERVA Electrophoresis GmbH, Heidelberg, Germany) and the mix was incubated at $37^{\circ} \mathrm{C}$ for $20 \mathrm{~min}$. FBS $(10 \%)$ was added to stop the enzymatic activity. The cell pellet was resuspended with $1 \mathrm{~mL}$ complete growth medium containing F-12 medium, $10 \%$ FBS, $100 \mathrm{U} /$ $\mathrm{mL}$ penicillin and $100 \mu \mathrm{g} / \mathrm{mL}$ streptomycin. After gentle pipetting, $80 \mu \mathrm{L}$ of dissociated cells at a density of $1 \times 10^{4}$ cells $/ \mathrm{cm}^{2}$ were seeded onto poly-D-lysine/laminin-coated coverslips (BD Biosciences, San Jose, CA, USA) in 24well plates. After $2 \mathrm{~h}$, cells were flooded with warm growth 
medium and cultured for 1 week, until use. Fresh medium was replaced on day 2 and 5 after seeding.

\section{In vitro culture protocol of DRG explants and primary neurons}

$2 \mathrm{~d}$ after DRG in vitro culture, fresh growth medium, composed of F-12 medium, $100 \mathrm{U} / \mathrm{mL}$ penicillin and $100 \mu \mathrm{g} / \mathrm{mL}$ streptomycin, was supplemented with $25 \mathrm{ng} / \mathrm{mL}$ TNF- $\alpha$ (Cell Signaling Technology, Danvers, MA, USA) in combination with various doses of curcumin $(0,0.1,1$ and $10 \mu \mathrm{M}$ dissolved in $0.1 \%$ Dimethyl sulphoxide (DMSO) in PBS) (Acros Organics, NJ, USA). Control group was treated with $0.1 \%$ DMSO in PBS. DRGs were cultured for other $24 \mathrm{~h}$ before further processing.

Primary neurons were treated with TNF- $\alpha(10 \mathrm{ng} / \mathrm{mL})$ and optimised dose of curcumin ( $10 \mu \mathrm{M}$ in $0.1 \%$ DMSO) and cultured for $2 \mathrm{~d}$ before following assays.

\section{Fluorescence immunostaining}

After culture for $7 \mathrm{~d}$ in vitro, neurons were fixed for 30 min with $4 \%$ paraformaldehyde (PFA), permeablised for 5 min with $0.3 \%$ Triton X-100, blocked for $1 \mathrm{~h}$ with $3 \%$ bovine serum albumin (BSA) at room temperature, incubated overnight at $4{ }^{\circ} \mathrm{C}$ with Pan Neuronal Marker primary antibodies $(1: 500$, EMD Millipore, Billerica, MA,USA) and visualised using Alexa Fluo594 goat anti-rabbit IgG (1:1000, Life Technologies). F-actin was stained with Alexa Fluo 488-phalloidin (1: 5000, Life Technologies) for $30 \mathrm{~min}$. Cell nuclei were stained with 4',6-diamidino-2-phenylindole (DAPI) (Life Technologies). Immunofluorescence images were taken under a Nikon Eclipse E600 fluorescence microscope and processed with NIS-Elements software (Nikon) (Xiao et al., 2016).

\section{RNA isolation, reverse transcription and real-time polymerase chain reaction (PCR)}

After $1 \mathrm{~d}$, total RNA was extracted from DRGs and neurons with Trizol reagent, according to the manufacturer's instruction (Life Technologies, Grand Island, NY, USA). DRGs were manually homogenised in a micro-size tissue grinder $(0.2 \mathrm{~mL})$. The concentration of RNA was determined using a Nanodrop spectrophotometer (Thermo Scientific)at $260 \mathrm{~nm}$. Reverse transcription of $0.5 \mu \mathrm{g}$ of RNA was performed with iScript Reverse Transcription Supermix (Bio-Rad) and the complementary DNA (cDNA) was diluted with nuclease-free water by either 5- (target genes) or 50-fold (reference gene). Quantitative PCR containing SYBR ${ }^{\circledR}$ Green master mix (Bio-Rad) was performed using $\mathrm{iQ}^{\mathrm{TM}} 5$ multicolour real-time PCR detection system (Bio-Rad, Hercules, CA, USA) with an annealing temperature of $55^{\circ} \mathrm{C}$ (Xiao et al., 2016). The mRNA expression of interleukin 6 (IL-6), prostaglandinendoperoxide synthase cyclooxygenase-2 (COX-2), anti-oxidative enzymes superoxide dismutase 2 (SOD2), catalase and haeme oxygenase-1 (HO-1) were evaluated. The 18S rRNA was used as an internal control. Sequences of primers, individual annealing temperature and amplicon lengths were the same as previously reported (Liu et al., 2013; Xiao et al., 2016).
Intracellular reactive oxygen species (ROS) detection in neurons

$2 \mathrm{~d}$ after curcumin and TNF- $\alpha$ treatment, neuronal cells were incubated for $30 \mathrm{~min}$ at $37^{\circ} \mathrm{C}$ with serum free F-12 medium containing $10 \mu \mathrm{M}$ 2', 7' dichlorodihydrofluorescein diacetate ( $\mathrm{H}_{2}$ DCFDA), washed twice with warm PBS and mounted onto slides for fluorescence imaging using a fluorescein isothiocyanate (green) filter, as described above.

\section{Terminal deoxynucleotidyl transferase dUTP nick end labelling (TUNEL) assay}

$2 \mathrm{~d}$ after curcumin and TNF- $\alpha$ treatment, cellular apoptosis was assessed using the TUNEL assay kit (Roche Applied Science, Indianapolis, IN, USA), as previously described (Liu et al., 2013). With ProLong Gold antifade reagent applied during the mounting step, TUNEL-positive (apoptotic) nuclei showed green fluorescence, whereas total nuclei displayed blue fluorescence. Fluorescence images were taken as previously described (Xiao et al., 2016).

\section{Western blotting}

After 5 and 24 h, DRGs (5-6/group) were pulverised in liquid nitrogen and lysed in $0.1 \mathrm{~mL}$ lysis buffer (radioimmunoprecipitation assay (RIPA) buffer supplemented with $1 \times$ proteinase inhibitor cocktail and phenylmethylsulphonyl fluoride (PMSF)). Lysates were subjected to sodium dodecyl sulphate polyacrylamide gel electrophoresis and transferred to a nitrocellulose membrane. After incubation for $1 \mathrm{~h}$ at room temperature with Odyssey ${ }^{\circledR}$ Blocking Buffer (LI-COR, Lincoln, NE, USA), membranes were incubated overnight at $4{ }^{\circ} \mathrm{C}$ with mouse phospho-ERK 1/2 (1:1000; Cell Signaling, Danvers, MA, USA), rabbit total ERK 1/2 (1:1000; Cell Signaling), rabbit phosphor-Akt1/2/3 (1 : 1000; Santa Cruz Biotechnology, Dallas, TX, USA) and rabbit total Akt1/2/3 (1 : 1000; Santa Crutz Biotechnology) antibodies, followed by incubation with a goat anti-mouse Alexa Fluo $680(1: 5000)$ or goat-anti-rabbit Alexa Fluo 800 (1: 5000; ThermoFisher Scientific) for $1 \mathrm{~h}$ at room temperature. Membranes were scanned and analysed with Odyssey ${ }^{\circledR}$ Infrared Imaging System (LI-COR) (Xiao et al., 2016).

\section{Enzyme linked immunosorbent assay (ELISA)}

After $24 \mathrm{~h}$, the supernatant of DRG explant culture was collected to analyse the contents of Substance P (R\&D system Minneapolis, MN, USA), IL-6 (eBioscience, San Diego, CA, USA) and prostaglandin E2 (PGE2, Thermo Scientific, Rockford, IL, USA) using corresponding ELISA kits, according to the manufacturers' instructions (Liu et al., 2013).

\section{Immunohistochemistry staining and quantification}

After $24 \mathrm{~h}$, DRGs were fixed for $30 \mathrm{~min}$ at room temperature in $4 \%$ PFA and, before optimal cutting temperature compound (OCT) embedding, soaked into $15 \%$ and $30 \%$ sucrose, sequentially. Cryosections $(5 \mu \mathrm{m})$ were obtained, treated for 30 min with $3 \%$ hydrogen peroxide in methanol, to block the endogenous peroxidase, 
blocked in $3 \%$ BSA in PBS and incubated overnight with monoclonal substance P (SP) antibody (1:400) (R\&D System, Minneapolis, MN, USA) or monoclonal calcitonin gene related peptide (CGRP) antibody (1:4000) (Sigma, a kind gift from Dr Erisir at the University of Virginia). The biotinylated goat anti-mouse secondary antibody (1 : 500, Vector Laboratories Inc., Burlingame, CA, USA) was used to detect both SP and CGRP. The standard 3,3'-diaminobenzidine (DAB) procedure was adopted to visualise the signal. Haematoxylin was used for counter-staining. Immunoglobulin $\mathrm{G}$ control was performed following identical procedures, excluding the primary antibody. The images were taken using a Nikon Eclipse E600 fluorescence microscope and analysed with NIS-Elements software (Nikon).

In the imaging software Nikon Elements, the colour hue settings were altered to provide the best contrast. The same colour hue settings were used throughout quantification. Several square regions of interest (ROI) with linear length of $144.5 \mu \mathrm{m}$, that adequately represented the entire quantifiable cell area, were used and analysed individually. A previously optimised object count threshold for intensity a

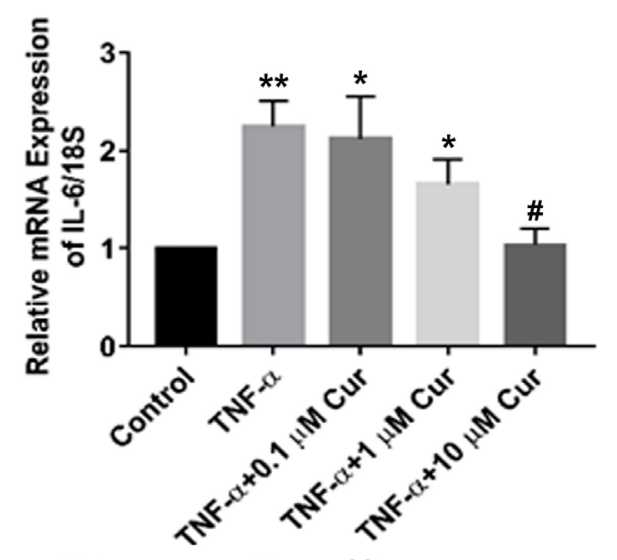

C
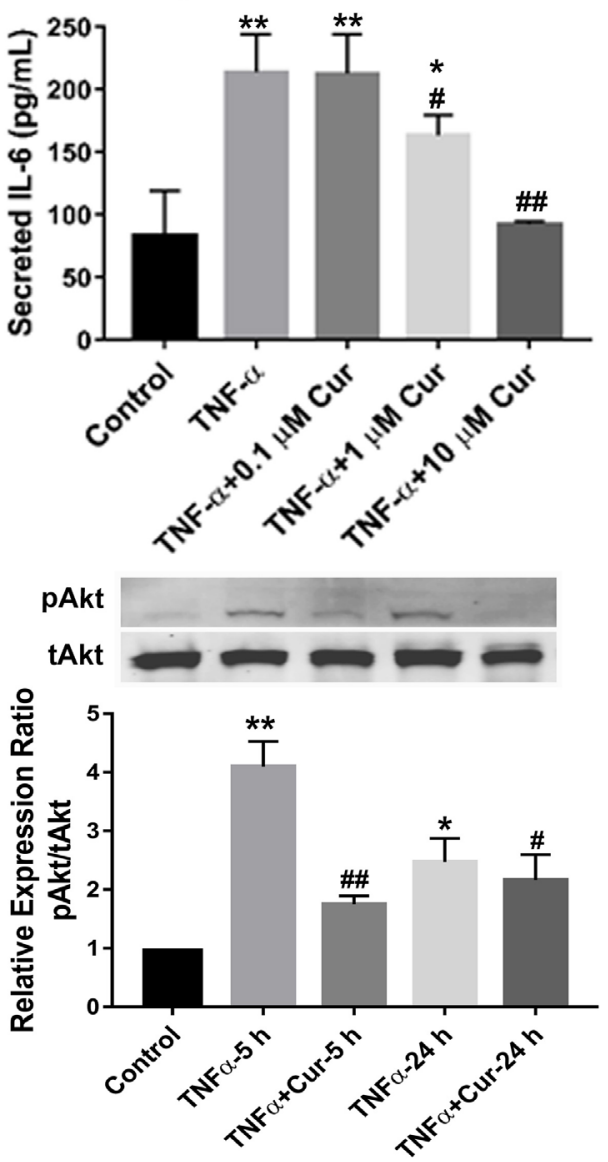

b

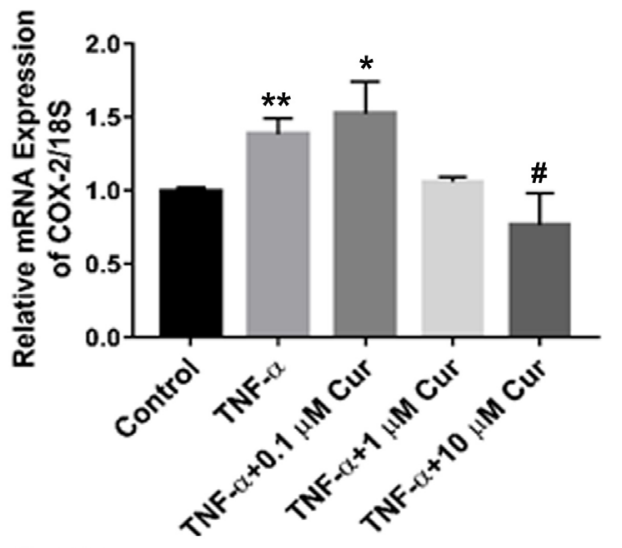

d

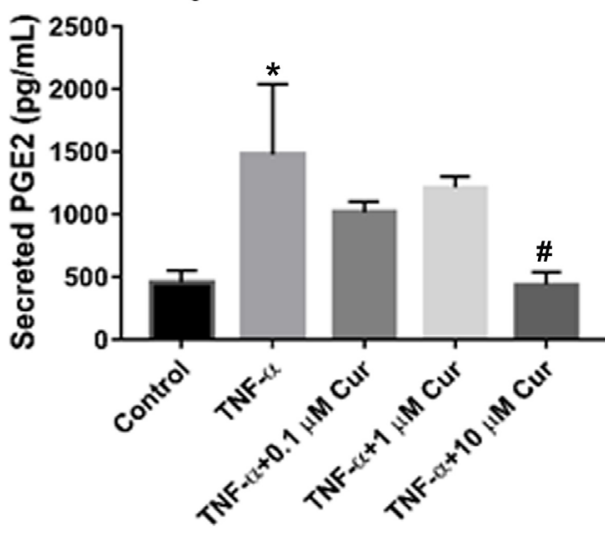

f

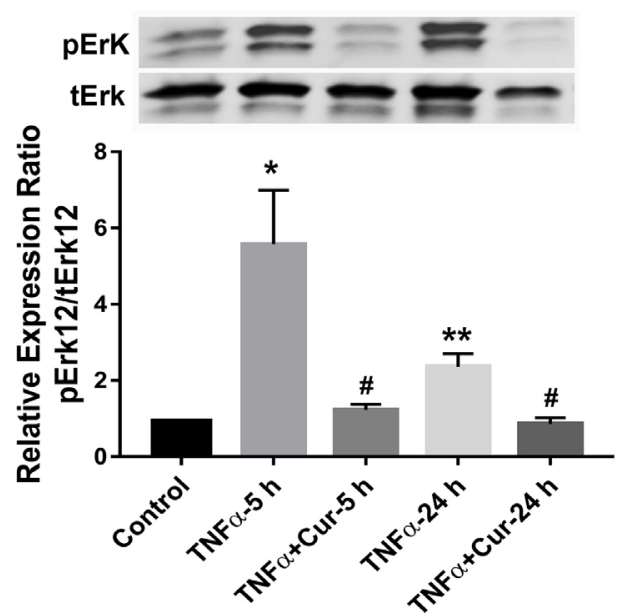

Fig. 1. Curcumin alleviated TNF- $\alpha$-induced neuroinflammation in mouse dorsal root ganglion explants. Curcumin suppressed mRNA expressions of (a) IL-6 and (b) COX-2 and protein expressions of (c) IL-6 and (d) PGE-2, in a dose dependent manner after co-treatment for $24 \mathrm{~h}$ with TNF- $\alpha(25 \mathrm{ng} / \mathrm{mL}) .5$ and $24 \mathrm{~h}$ post treatment, curcumin $(10 \mu \mathrm{M})$ prevented TNF- $\alpha$-induced increased phosphorylation of (e) Akt and (f) Erk, as detected by western blotting and quantified by densitometry analysis. ${ }^{*} p<0.05,{ }^{* *} p<0.005 v s$. control; ${ }^{*} p<0.05,{ }^{\#} p<0.005 v s$. TNF- $\alpha$ group at 5 or 24 h. $n=6$ groups of DRGs (5-6 DRGs per group) for each experiment. 
quantification (brown and blue in this case) was loaded and kept consistent throughout quantification. Each ROI per image was calculated and used to determine an image average. About three image averages were used to give a value for a particular DRG and at least five DRGs were analysed to determine mean value of one treatment group. The colour intensity ratio of brown to blue was calculated for each group, shown as \% of immuno-positive areas.

\section{Mouse radiculopathy model secondary to disc herniation}

The use of animals was approved by the Institutional Animal Care and Use Committee at the University of Virginia. Balb/C mice were purchased from Envigo (Indianapolis, IN, USA. 8-10 weeks old, male, 20-25 g). General anaesthesia was induced with intraperitoneal injection of ketamine/xylazine (60-80/5-10 mg/kg). Briefly, using aseptic technique and a surgical microscope, the spine was exposed through an anterior midline transperitoneal approach. After separating the hind peritoneum and psoas major muscle, the L4 and L5 vertebral bodies were identified. The left L5 nerve root was exposed by removing the overlying psoas muscle fibres and the L4-5 disc was punctured laterally, to enable nucleus protrusion towards the L5 nerve root. After surgery, animals were randomly assigned to two groups: curcumin $(n=5)$ and $\operatorname{DMSO}(n=5)$. For the curcumin group, curcumin solution ( $1 \mathrm{mg}$ in $40 \mu \mathrm{L}$ DMSO, per $20 \mathrm{~g}$ body weight) was given by intraperitoneal injection every other day from postoperation day (POD) 0 up to POD 10 (total 6 injections). For the DMSO group, the same amount of DMSO solvent was given as a vehicle control. A sham operated group exhibited unchanged baselines (data not shown).

\section{Measurement of mechanical sensitivity (electronic von Frey)}

To assess the mechanical sensitivity of animals subjected to disc herniation with or without curcumin treatment, the electronic von Frey test was performed on both ipsilateral and contralateral hind paws for 3 consecutive days prior to surgery and every other day from POD 1 to POD 12 in a blinded fashion, following reported protocol (Martinov et al., 2013). In brief, mice were acclimated on an elevated mesh grid and mechanical sensitivity was determined using the up-down method with the electronic von Frey apparatus, as described (Bonin et al., 2014). Five trials were conducted on each paw, with at least 5 min rest time between trials on opposite paws and $10 \mathrm{~min}$ between trials on the same paw. For each paw, mechanical threshold from 5 trials were averaged after excluding the maximum and minimum reading. Both ipsilateral and contralateral mechanical thresholds of both curcumin and DMSO groups were measured and mean threshold value of each group was averaged at each time point.

\section{Micro-computed tomography $(\mu \mathrm{CT})$ scan and disc height measurements}

2 weeks after surgery, mice were euthanised in a $\mathrm{CO}_{2}$ chamber and spines were dissected and fixed in $10 \%$ formalin. $\mu \mathrm{CT}$ scans ( $n=3$ per group), performed on a $\mu \mathrm{CT}$ system $(70 \mathrm{kV}, 114 \mu \mathrm{A}$; $\mu \mathrm{CT} 80$ scanner; Scanco
Medical, Bassersdorf, Switzerland), were reconstructed with an isotropic voxel size of $10 \mu \mathrm{m}$. Multi-level thresholds procedure (threshold for bone $=205$ ) was applied to discriminate vertebral column from disc. Threedimensional images were acquired for qualitative and quantitative evaluation in an X-ray image mode. Heights of discs (L4-5 and L5-6) and vertebral bodies (L4, L5 and L6) were measured using Image J software by measuring lengths of a straight vertical line connecting anterior-toanterior, midline-to-midline and posterior-to-posterior sections of discs and vertebral bodies, as shown in Fig. 5d. For both L4-5 and L5-6 discs, the percentage disc height $(\mathrm{PDH})$ was calculated as follows: $\mathrm{PDH}=(\mathrm{d} 1+\mathrm{d} 2+\mathrm{d} 3) /$ $(\mathrm{d} 1+\mathrm{d} 2+\mathrm{d} 3+\mathrm{v} 1+\mathrm{v} 2+\mathrm{v} 3)$. A relative PDH ratio of L4-5 to L5-6 discs, in which PDH of L5-6 was regarded as an internal control, was calculated.

\section{Alcian blue/picrosirius red staining}

After fixation, spines were decalcified in $0.25 \mathrm{M}$ ethylenediaminetetraacetic acid for 2 weeks (Jin et al., 2013). Paraffin embedded sections $(7 \mu \mathrm{m})$ were subjected to $1 \%$ alcian blue solution $(\mathrm{pH} 2.5)$ and picrosirius red $(0.1 \%$ sirius red in saturated aqueous picric acid) for alcian blue/picrosirius red staining, following published protocol (Walter et al., 2015).

\section{Statistical analysis}

For in vitro experiments, data obtained from three biological and three technical replicates were analysed and presented as mean \pm SEM. One-way ANOVA was used to analyse pain data using GraphPad Prism software (GraphPad Software, Inc.). Data comparing two groups were analysed with Student's $t$-test. Effect size of in vivo study was conducted using mean and standard deviation based on Cohen's $d$ calculation. A $p$-value lower than 0.05 was considered statistically significant.

\section{Results}

\section{Curcumin attenuated TNF- $\alpha$-induced} neuroinflammation in a dose-dependent manner

As shown in Fig. 1a,c, $24 \mathrm{~h}$ treatment with TNF- $\alpha$ significantly increased mRNA expression and secretion of IL-6, compared to control DRGs $(* * p<0.01 v s$. control), while curcumin reversed this effect in a dose-dependent manner. $10 \mu \mathrm{M}$ of curcumin was the most effective dose within these experimental conditions $\left({ }^{*} p<0.05 v s\right.$. control, ${ }^{\#} p<0.05$ for mRNA and ${ }^{\# \#} p<0.01$ for released protein $v s$. TNF- $\alpha$ group). Similarly, $10 \mu \mathrm{M}$ of curcumin reduced TNF- $\alpha$-induced increased mRNA expression of COX-2 $\left(*_{p}<0.05, * *_{p}<0.01 v s\right.$. control, ${ }^{*} p<0.05 v s$. TNF- $\alpha$ group) (Fig. 1b). Accordingly, PGE2 was also significantly increased upon TNF- $\alpha$ stimulation ( ${ }^{*} p<0.05 v s$. control), which was again attenuated to the basal level by $10 \mu \mathrm{M}$ of curcumin $\left({ }^{\#} p<0.05 v s\right.$. TNF- $\alpha$ ) (Fig. 1d). At both 5 and $24 \mathrm{~h}$ time points, TNF- $\alpha$ activated protein kinase B (AKT) and ERK phosphorylation $(* p<0.05, * * p<0.005 v s$. control), whereas curcumin, at the most promising dose of $10 \mu \mathrm{M}$, significantly downregulated TNF- $\alpha$-induced AKT and ERK phosphorylation $\left({ }^{\#} p<0.05\right.$, ${ }^{\#} p<0.005$ 
$v s$. TNF- $\alpha$ ) (Fig. 1e,f). These results confirmed curcumin's effect in antagonising TNF- $\alpha$-induced neuroinflammation in DRG explant culture, possibly via AKT and ERK pathways.

Curcumin protected against cellular apoptosis and alleviated neuroinflammation in primary neurons To identify isolated neurons, Pan Neuronal Marker was employed to react against key somatic, nuclear, dendritic and axonal proteins distributed across the pan neuronal architecture. After $7 \mathrm{~d}$ of culture, through immunofluorescence staining, purity of isolated neurons was shown to be $\sim 60-70 \%$, by counting neuronal cells (red Pan Marker) vs. total cells (DAPI stained blue nuclei, Fig. 2a) (5 random areas were analysed). Cellular apoptosis was measured by TUNEL assay, detecting the cleavage of genomic DNA during apoptosis. TNF- $\alpha$ significantly increased the percentage $(>50 \%)$ of apoptotic (green a
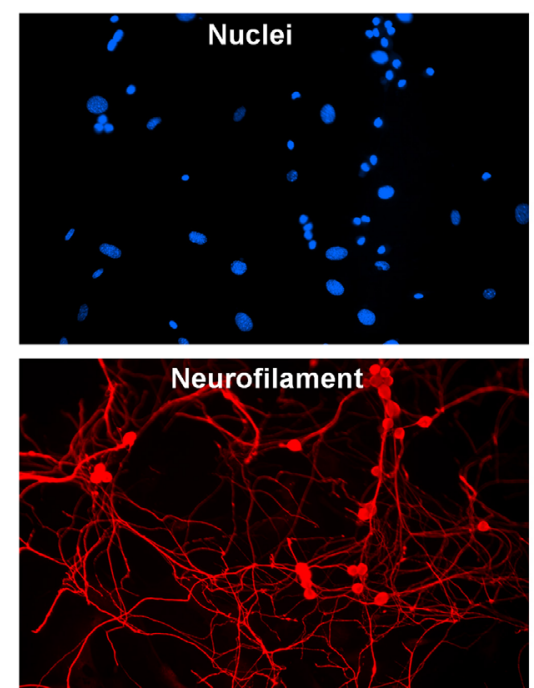

b

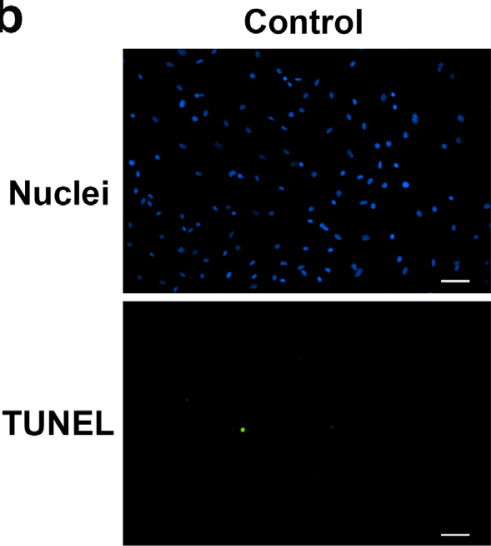

C

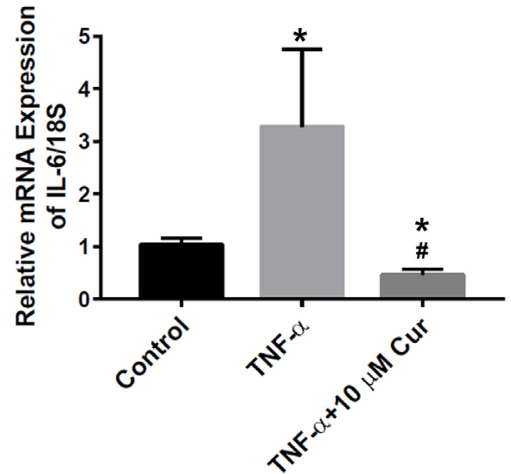

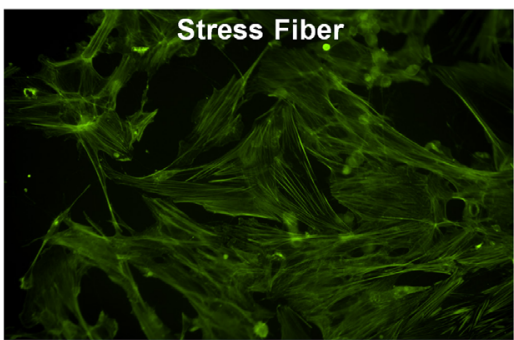

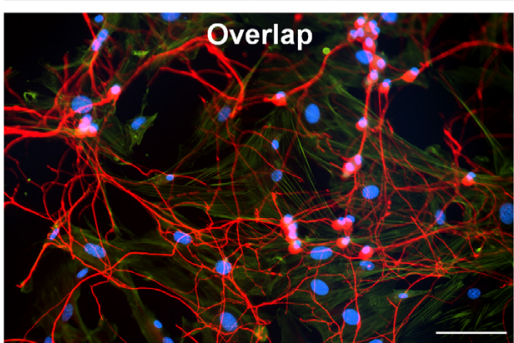

TNF- $\alpha+10 \mu M$ Curcumin

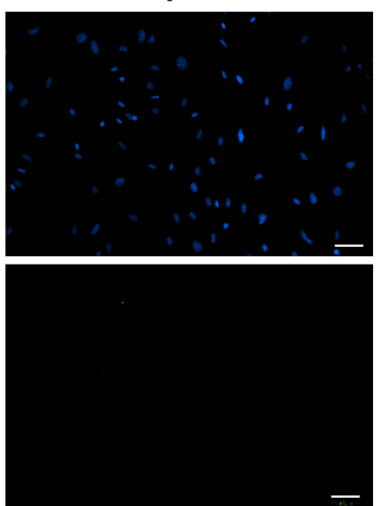

d

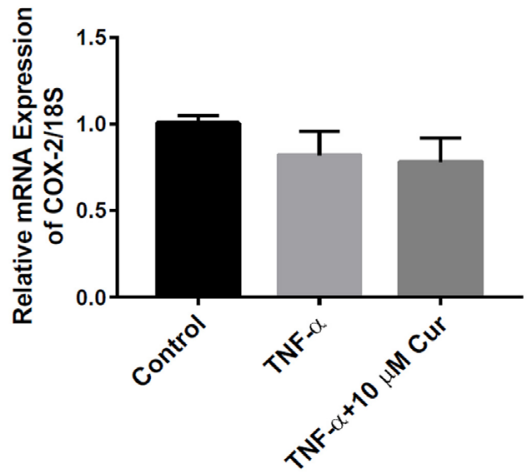

Fig. 2. Curcumin protected primary neurons from TNF- $\alpha$-induced apoptosis and neuroinflammation. (a) Immunofluorescence staining showed high purity ( $>80 \%$ ) of isolated neurons (red, neurofilaments; green, actin stress fibres; blue, nucleus). (b) $48 \mathrm{~h}$ after treatment, curcumin $(10 \mu \mathrm{M})$ rescued TNF- $\alpha(10 \mathrm{ng} / \mathrm{mL})$-induced neuron cellular apoptosis. (c) $48 \mathrm{~h}$ after treatment in neurons, curcumin suppressed both basal and TNF- $\alpha(10 \mathrm{ng} / \mathrm{mL})-$ induced mRNA expression of IL-6. (d) TNF- $\alpha(10 \mathrm{ng} / \mathrm{mL})$, in the presence or absence of curcumin $(10 \mu \mathrm{M})$, did not significantly alter the expression of COX-2 in neurons, $48 \mathrm{~h}$ after treatment. ${ }^{*} p<0.05$ vs. control; ${ }^{*} p<0.05$ $v s$. TNF- $\alpha$ groups. $n=6$ groups of DRGs (5-6 DRGs) per group for each experiment. 
a
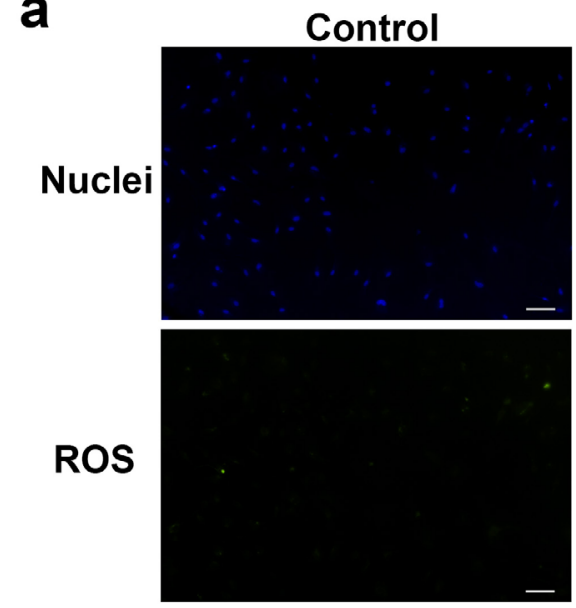

b

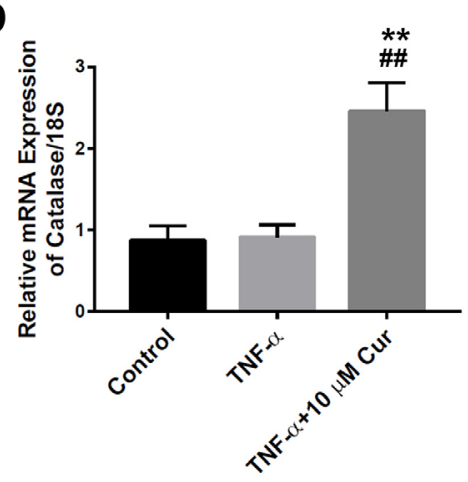

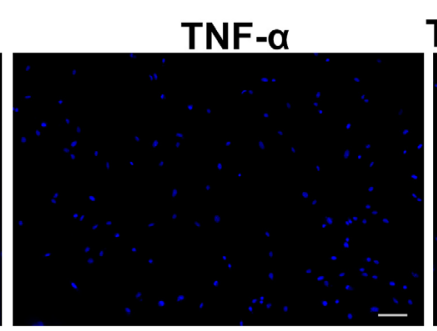

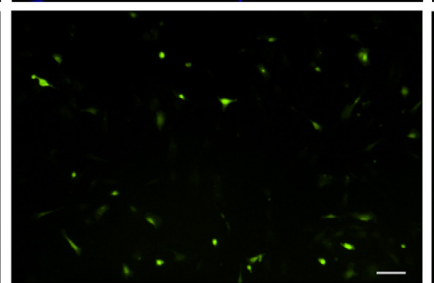

C

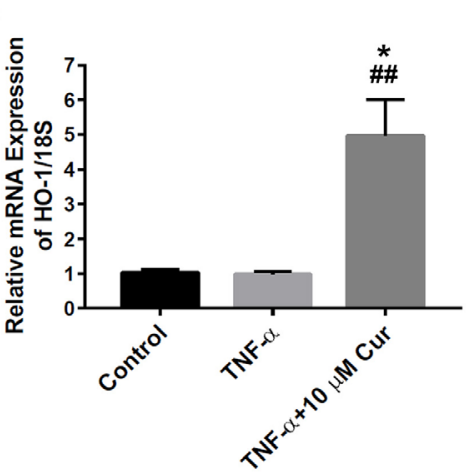

TNF- $\alpha+10 \mu M$ Curcumin
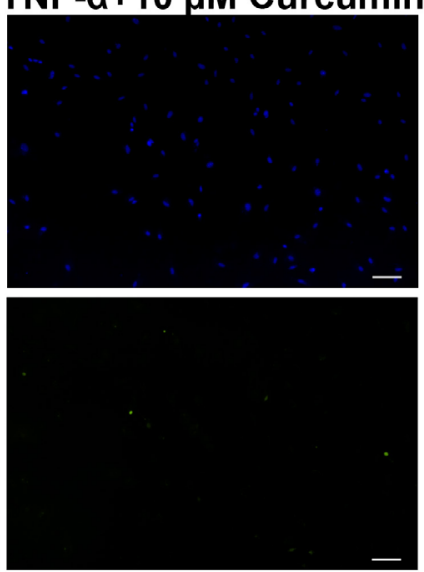

d

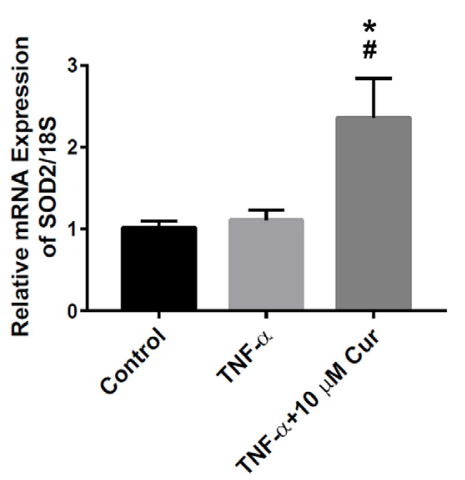

Fig. 3. Curcumin restored TNF- $\alpha$-stimulated excessive ROS production in primary neurons and increased the expression of anti-oxidative enzymes. (a) $10 \mu \mathrm{M}$ of curcumin significantly quenched excessive intracellular ROS production $48 \mathrm{~h}$ after TNF- $\alpha(10 \mathrm{ng} / \mathrm{mL})$ stimulation. Coincidently, $48 \mathrm{~h}$ after treatment, curcumin $(10 \mu \mathrm{M})$, but not TNF- $\alpha(10 \mathrm{ng} / \mathrm{mL})$, significantly increased mRNA expression of the anti-oxidative enzymes (b) catalase, (c) HO-1 and (d) SOD2. ${ }^{*} p<0.05,{ }^{*} p<0.005 v s$. control; ${ }^{\#} p<0.05,{ }^{\#} p<0.005 v s$. TNF- $\alpha$ group. Note: microscopic images were taken at $100 \times$ magnification. Scale bar $=100 \mu \mathrm{m} . n=6$ neuron seeded cover slips for each experiment.

fluorescence) to total cells (blue fluorescence), when compared with the control group. In contrast, $48 \mathrm{~h}$ after treatment, curcumin $(10 \mu \mathrm{M})$ completely prevented TNF$\alpha$-induced neuron apoptosis (Fig. 2b). Meanwhile, the mRNA expression of IL- 6 was increased in TNF- $\alpha$-treated neurons $(* p<0.05 v s$. control), while curcumin decreased it to the basal level ( ${ }^{*} p<0.05 v s$. control, ${ }^{*} p<0.05 v s$. TNF- $\alpha$ group) (Fig. 2c). The mRNA expression of COX-2 was not changed in the presence of TNF- $\alpha$ with or without curcumin treatment (Fig. 2d).

\section{Curcumin markedly reduced TNF- $\alpha$-induced excessive ROS generation}

To evaluate the anti-oxidative effects of curcumin, we performed fluorescence staining using $\mathrm{H}_{2}$ DCFDA as an indicator of intracellular ROS content. Upon cleavage of the acetate groups by intracellular oxidation, the non-fluorescent $\mathrm{H}_{2}$ DCFDA is converted to the highly fluorescent 2', 7'-dichlorofluorescein (DCF). As shown in Fig. 3a, TNF- $\alpha$ stimulation increased the production of ROS. The percentage of ROS-positive cells (green) was $\sim 40-50 \%$ in TNF- $\alpha$-treated neurons vs. less than $1 \%$ inthe control group. $48 \mathrm{~h}$ after the treatment, $10 \mu \mathrm{M}$ curcumin significantly quenched the ROS production to the basal control level. In addition, curcumin promoted
mRNA expression of various anti-oxidative enzymes, including catalase (Fig. 3b), haem oxygenase-1 (Fig. 3c) and SOD2 (Fig. 3d) by 2-3 folds, compared to both control $(* p<0.05, * * p<0.005)$ and TNF- $\alpha$-treated group ( $\left.{ }^{\#} p<0.05,{ }^{\# \#} p<0.005\right)$ - although TNF- $\alpha$ stimulation did not alter expression of those genes significantly (Fig. 3b-d). These results suggested an important function of curcumin in the modulation of mitochondrial activity via upregulation of anti-oxidative enzymes against TNF- $\alpha$ induced oxidative stress.

\section{Curcumin decreased TNF- $\alpha$-induced neuropeptide release}

Neuropeptides substance P and CGRP expression in neurons are induced or upregulated following inflammation and, accordingly, are considered a signal of neuronal damage, secreted to induce repair mechanisms and supportive glial reactions (Ringer et al., 2016). Expressions of substance P and CGRP in DRGs were visualised by immunohistochemistry (Fig. 4a). Upon 24 h treatment with TNF- $\alpha$, the percentage of substance P and CGRP immunopositive cells (dark brown stained cells) was increased significantly in DRG tissue compared to the control ( $* p<0.05 v s$. control) and was reversed to the basal level upon treatment with $10 \mu \mathrm{M}$ of curcumin ${ }^{\# \# \#} p<0.001$ 
vs. TNF- $\alpha$ ) (Fig. 4b,c). Also, the elevation of substance P, confirmed by ELISA assay performed on culture medium of DRG explants after TNF- $\alpha$ stimulation $\left({ }^{*} p<0.05 v s\right.$. control), was inhibited by curcumin as low as $0.1 \mu \mathrm{M}$ $\left({ }^{\#} p<0.05 v s\right.$. TNF- $\alpha$ ) (Fig. 4d). These results provided both qualitative and quantitative evidence of curcumin's effect in antagonising TNF- $\alpha$ elicited neuropeptide synthesis and release.

\section{Systemic administration of curcumin alleviated} hyperalgesia in a mouse radiculopathy model

In our newly established radiculopathy mouse model induced by lumbar disc herniation, mechanical sensitivity (von Frey) of animals was evaluated every other day up to $12 \mathrm{~d}$ post-surgery ( $n=5$ per group). For the ipsilateral side, curcumin treatment (intraperitoneal injection every other day) effectively restored the dramatically decreased

a

Control

0
0
$\frac{1}{\pi}$
0
0
0
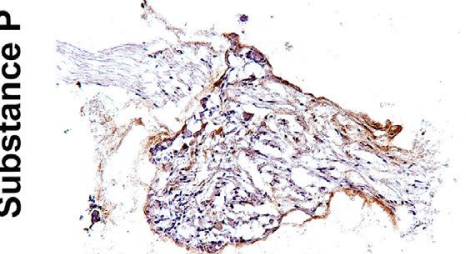

TNF- $\alpha$

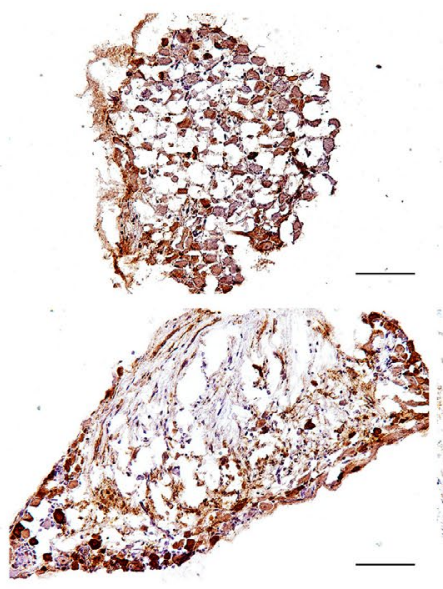

TNF- $\alpha+10 \mu M$ Curcumin
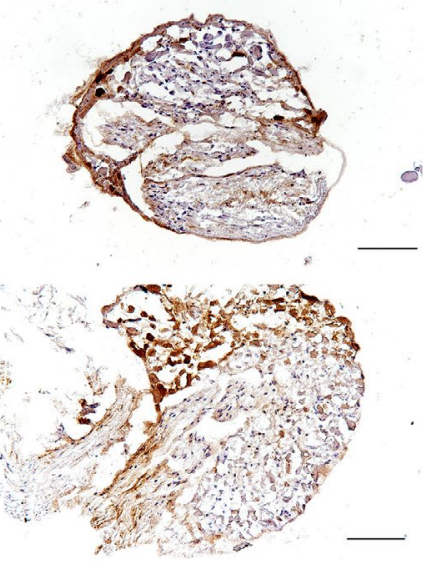

b

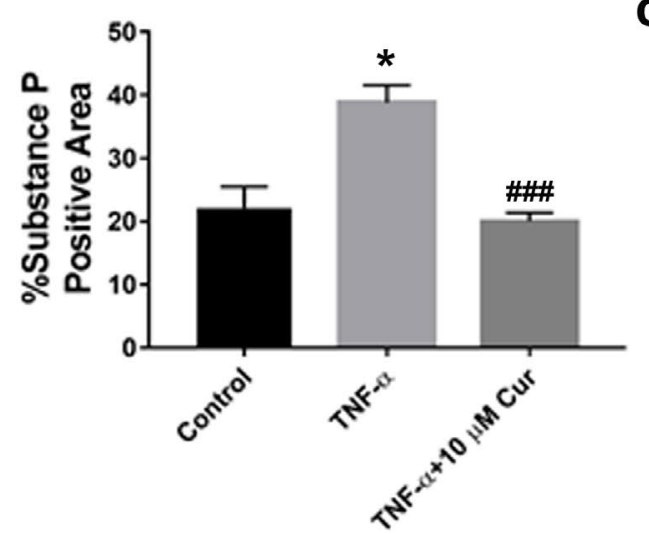

C

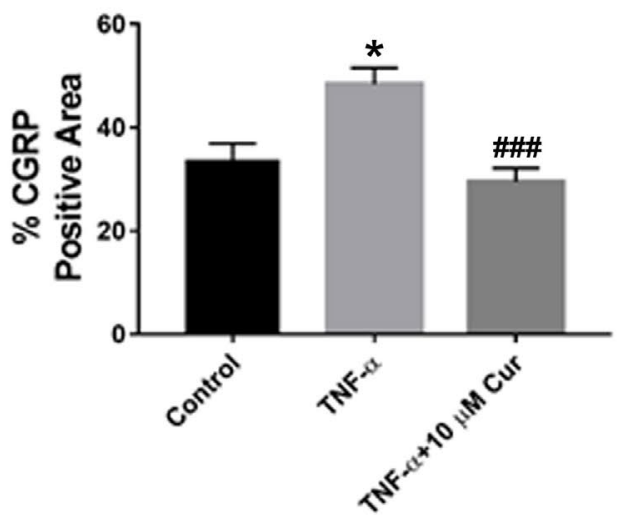

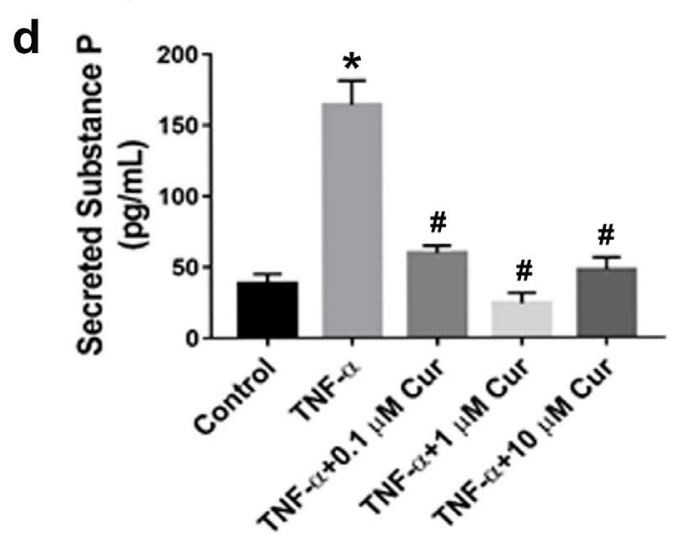

Fig. 4. In DRG explant culture, curcumin attenuated TNF- $\alpha$-elicited synthesis and release of neuropeptides substance $\mathrm{P}$ and CGRP. (a) Immunohistochemical staining suggested that curcumin $(10 \mu \mathrm{M})$ significantly alleviated TNF- $\alpha$ (25 ng/mL)-elicited synthesis of substance P (upper row) and CGRP (lower row) in DRG explants, after $24 \mathrm{~h}$ of co-treatment. (b,c) Quantitative analysis of substance P and CGRP positive areas of the immunostained images in (a). (d) ELISA assay confirmed that, in DRG culture medium, after $24 \mathrm{~h}$ of treatment, curcumin $(10 \mu \mathrm{M})$ attenuated TNF- $\alpha(25 \mathrm{ng} / \mathrm{mL})$-promoted substance P release. ${ }^{*} p<0.05$ for curcumin $v s$. DMSO group and $v s$. control; ${ }^{*} p<0.05$ and ${ }^{\# \#} p<0.0005$ vs. TNF- $\alpha$ group. Scale bar $=100 \mu \mathrm{m} . n=5-7$ DRGs per group. 
mechanical threshold caused by disc herniation to a presurgery level already at POD $2(* p<0.05, * * p<0.01$ vs. DMSO group) (Fig. 5a). The contralateral threshold of curcumin group showed no significant difference compared to the DMSO group at all time points, except a slight difference at POD $4(* * p<0.01)$ (Fig. 5b). The final mean of von Frey threshold in curcumin treated group was significantly higher than that of non-treated control group $(p<0.005)$, with a very large effect size (Cohen's $d=2.095)$. As shown in Fig. 5d, animal body weight dropped within $4 \mathrm{~d}$ post-surgery and gradually recovered afterwards, indicating that the acute pain caused by surgery might affect the overall health of mice and, accordingly, their mechanical sensitivity in the first few days. No dramatically different body weights were noticed between those two groups and the curcumin group showed improved and pain free movement and behaviour (supplementary video).

a

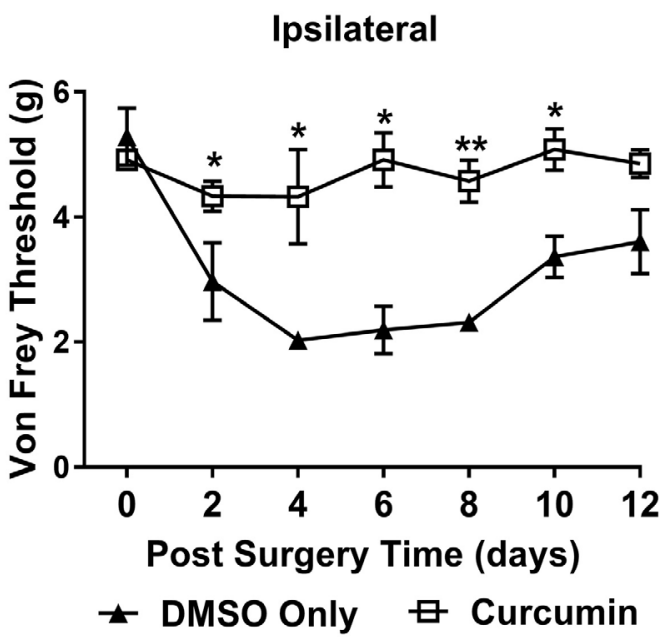

C

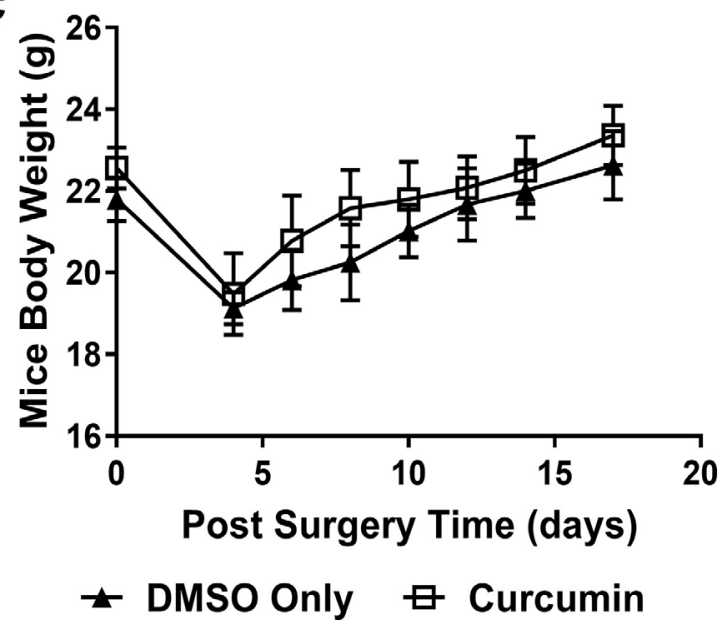

$\mu \mathrm{CT}$ images suggested that curcumin tended to maintain disc height of injured disc L4-5, although no statistical significance could be obtained due to a relative small sample size ( $n=3$ per group) for this measurement (Fig. 5d). These data demonstrated that curcumin alleviated radiculopathy and showed a tendency to prevent disc height loss following disc herniation surgery.

\section{Histology confirmed disc regeneration effect of curcumin}

Alcian blue, picrosirius red and haematoxylin staining allow a distinct visualisation of collagen (red), proteoglycans (blue) and cellular components on the same histological section. For this reason, they were used to examine structural changes in injured mouse disc with or without curcumin treatment (Gruber et al., 2002). As shown in Fig. $6 \mathbf{a}, \mathbf{b}, 2$ weeks after injury, injured mouse disc underwent

b
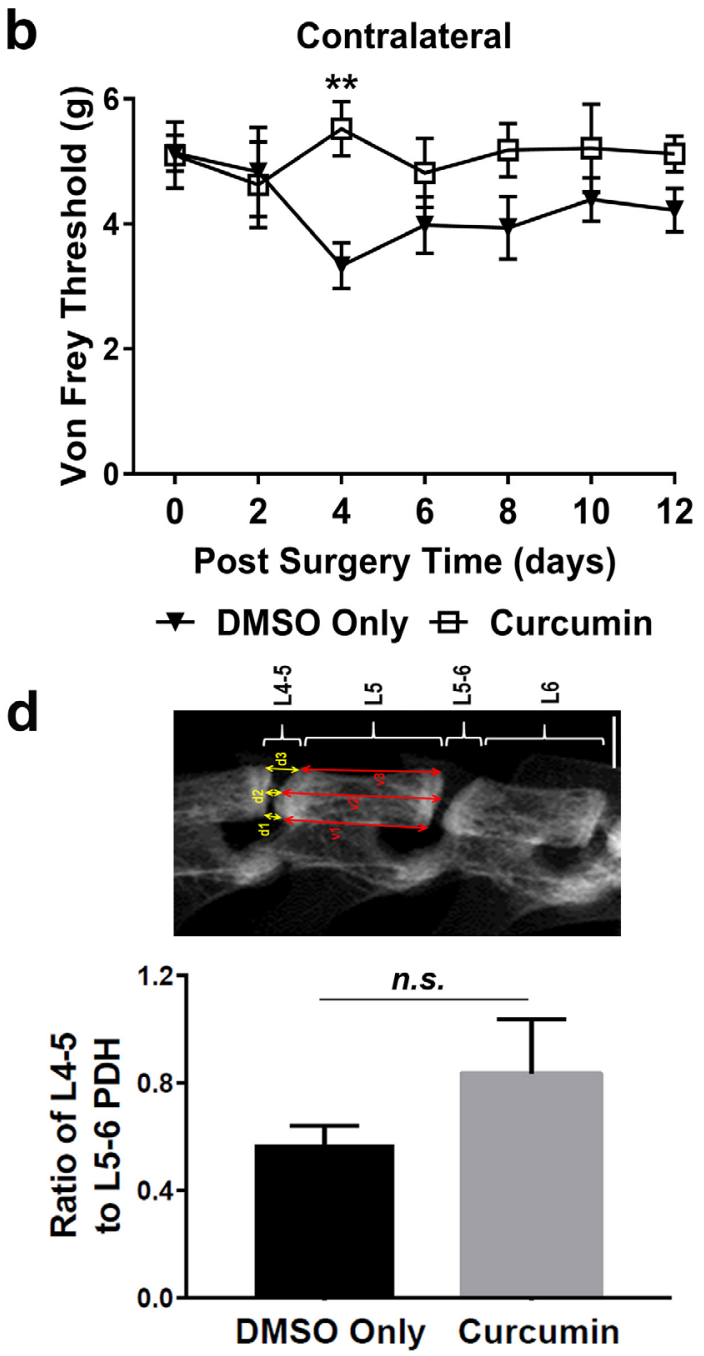

Fig. 5. Curcumin alleviated the ipsilateral mechanical hyperalgesia in a disc herniation mouse model. (a) Intraperitoneal administration of curcumin ( $1 \mathrm{mg}$ in $40 \mu \mathrm{L}$ DMSO, per $20 \mathrm{~g}$ body weight) every other day restored ipsilateral mechanical hyperalgesia secondary to disc herniation in mice up to POD 12, measured using the electronic von Frey up-down method; whereas (b) neither the disc injury nor the curcumin treatment altered the mechanical threshold on the contralateral side. (c) A steadily increasing animal body weights after POD 4 indicated an overall good recovery of tested animals. (d) Representative $\mu$ CT image of mouse spine two weeks after surgery indicated that curcumin might have a tendency to improve disc height of injured IVD. Note: five mice were used in each group. 
classical degenerative structural changes, such as unclear boundary between AF and NP regions, enlarged and proliferated chondrocytes within the prior NP region, ruptured endplates and AF lamina, when compared to the adjacent intact control IVD (Fig. 6c). Intriguingly, curcumin treatment group showed larger formation of collagen and proteoglycan (dark purple, due to combination of blue and red) in the inner AF zone and increased collagen (red) synthesis in the outer AF layers, compared to the intact and disc injury groups, indicating an ongoing regenerative process. This regenerative trend of curcumin was observed in all the animals of the current study.

\section{Discussion}

Although the pathogenesis of lumbar radiculopathy has not been fully elucidated, intervertebral disc (IVD) herniation associated inflammation and pro-inflammatory cytokines, such as TNF- $\alpha$, play a central role (Belavý et al., 2016; Guterl et al., 2013; Jin et al., 2013; Kepler et al., 2013). Current symptoms relief therapies using epidural steroid injection or TNF- $\alpha$ antagonist are neither effective nor safe. Therefore, to fulfil this urgent medical need, innovative research, in the direction of drug discovery and development, should be greatly emphasised. Desired therapeutics should at least address both inflammation and pain, during such chronic radiculopathy. In addition to efficacy, drug safety, with negligible toxicity, should be accentuated. Meanwhile, molecular homogeneity, with accurately defined chemical structure, might be given preference, due to a foreseen smoother roadmap along the regulatory processes. Based on these principles, we identified curcumin, a non-toxic natural compound found in an Indian spice, as a promising therapeutic candidate for lumbar radiculopathy secondary to disc herniation. As shown in our schematic hypothesis (Fig. 7), in DRG explants and primary neuron cultures, we studied several aspects of curcumin for its synergistic effects against neuroinflammation, oxidative stress and neuropeptides, which ultimately delivered analgesic outcome in a mouse model of lumbar radiculopathy caused by disc herniation.

Traditionally, curcumin belongs to the "dirty drug" category that exhibits multi-faceted functions, acting on different molecular targets or receptors in the body. Although "smart drugs" with selective action/binding site have been preferred by pharmaceutical companies in order to minimise potential adverse effects, multi-functional pleiotropic molecules, such as curcumin, have demonstrated great advantages in various pathological conditions due to high potency and negligible toxicity. Curcumin has been widely reported as an anti-inflammatory, anti-cancer and anti-infection agent. It is known to physically bind to 33 different proteins, including thioredoxin reductase, $\mathrm{COX} 2$, protein kinase $\mathrm{C}$ (PKC), 5-lipoxygenase (5-LOX) and tubulin (Zhou et al., 2011). Also, it can modulate nuclear factor- $\mathrm{BB}$ (Rahimifard et al., 2017), growth factors, cytokines, enzymes and genes regulating cell proliferation and apoptosis, as well as microglia/macrophage or T cellmediated immune response ( $\mathrm{Tu}$ et al., 2012). Although similar analgesic effects of curcumin were observed in various neuropathic animal models, the underlying mechanism varied from one study to another. For instance, studies suggested that curcumin could inhibit $\mathrm{H} 3$ and $\mathrm{H} 4$ acetylation in DRG, downregulate mGlu2 receptors in the spinal cord (Zammataro et al., 2014) and ameliorate CX3CR1 expression through the activation of NF- $\mathrm{BB}$ p65 in spinal cord and DRG of a CCI rat model (Cao et al., 2014). Moreover, curcumin decreases the expression of $\mathrm{pERK}, \mathrm{pJNK}$ and $\mathrm{pNR} 1$ activated by nerve ligation (Jeon et al., 2013) and attenuates TTX-R sodium currents of smallsized DRG neurons isolated from diabetic neuropathic pain rats (Meng et al., 2015). In addition, a histological study of nerve crush model, using stereological methods, revealed that curcumin restored and protected mean cell volume, total volume (A- and B-cells) and total surface of DRG cells, total number, diameter and area of the myelinated nerve fibres (Noorafshan et al., 2011a; Noorafshan et al., 2011b).

Our results revealed that curcumin significantly suppressed TNF- $\alpha$-induced neuroinflammation (IL-6, PGE2, COX-2) in DRG explant culture, possibly via AKT and ERK pathways (Fig. 1). Correspondingly, curcumin demonstrated a similar effect of antagonising TNF- $\alpha-$ elicited neuroinflammation (IL-6) in isolated primary neurons (Fig. 2). Of note, a small number of fibroblasts $(<20 \%)$ were sufficient for the success of seeding and survival of neurons in vitro,. However, they might also compromise results and cause data discrepancy between DRG and neurons, such as the mRNA expression of COX-2. Furthermore, curcumin exhibited a strong neuroprotective effect against TNF- $\alpha$-induced neuronal apoptosis, to which it might contribute by directly quenching the intracellular production of excessive ROS species and/or mRNA expression of anti-oxidative enzymes (HO-1, Catalase, SOD2) modulating mitochondria activities (Fig. 3). These findings correlated with the reported neuroprotective role of curcumin, such as against rotenone induced Parkinson's disease in mice (Khatri and Juvekar, 2016) and thus provided additional mechanistic justification for using curcumin to treat neuropathic pain.

The neuropeptide substance $\mathrm{P}$ is commonly expressed in primary sensory neurons and is commonly regarded as a pain neurotransmitter (Jo et al., 2016). Calcitonin gene related peptide (CGRP), a pro-nociceptive neuropeptide, has been shown to have increased synthesis and release in several types of neuropathic pain. Both substance $P$ and CGRP have been extensively studied in a variety of neuropathic pain models and a few reports have been published regarding their roles in radicular pain secondary to IVD degeneration. During the painful IVD degeneration, substance $\mathrm{P}$ is released into the extracellular matrix from disc cells and it potentially upregulates the production of matrix degrading enzymes, sensitises nerves and causes nociceptive transmission and chronic low back pain (La Binch et al., 2014; Purmessur et al., 2008; Richardson et al., 2009). Similarly, CGRP was also shown to be expressed in DRG neurons that innervate degenerated IVDs (Krock et al., 2014), where, in a mouse model of IVD injury, such expression was suppressed by intradiscal injection of IL-6 inhibitor (Sainoh et al., 2015). In our study, we performed quantitative analysis on the immunohistological staining 
of DRG samples and observed that curcumin significantly reversed TNF- $\alpha$-stimulated synthesis and release of both substance P and CGRP (Fig. 4). Our data revealed another important role of curcumin in regulating nociceptive pathways against TNF- $\alpha$-elicited neuropathic pain.

Neuropathic pain is among the most difficult types of chronic pain to treat, which not only significantly impairs patients' quality of life (McDermott et al., 2006), but also causes the burden of direct and indirect medical costs. Neuropathic pain can be characterised by disproportionate hypersensitivity to stimuli (hyperalgesia), abnormal pinsand-needles or electric-shock-like sensations (hyperpathia) and, finally, nociceptive responses to non-noxious stimuli (allodynia). Although the aetiology of neuropathic pain has not reached a common consensus, the intricate link between TNF- $\alpha$ and neuro-inflammatory signalling systems has drawn attention in the development of drugs to resolve the neuropathic pain (Leung and Cahill, 2010). In this perspective, systemic administration of curcumin has been shown to effectively alleviate neuropathic pain in several animal models, such as chronic constrictive injury (Zammataro et al., 2014) and diabetic neuropathic pain (Meng et al., 2015). Our study, performed monitoring the animal behaviour for up to two weeks after surgery, suggested that curcumin significantly attenuated ipsilateral mechanical hyperalgesia caused by disc herniation (Fig. 5). To the best of our knowledge, this is the first proof of the analgesic effect of systemic administered curcumin in

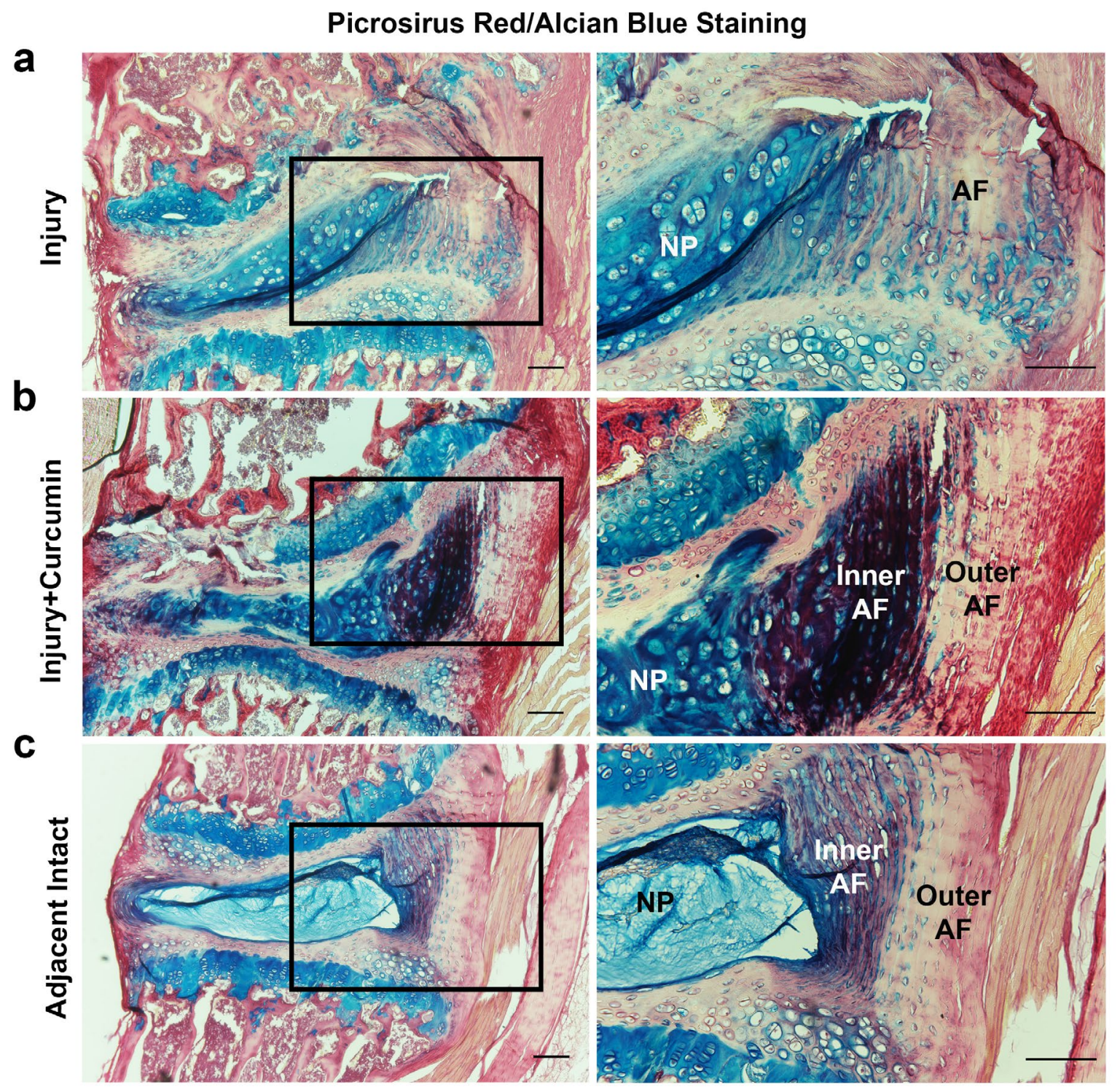

Fig. 6. Alcian blue/picrosirius red staining confirmed degenerative change and a regenerative process of injured IVD after peritoneal curcumin administration. Two weeks post-surgery, both (a) injury and (b) injury + curcumin groups demonstrated classical manifestations of disc degeneration, such as ruptured AF lamina, enlarged and proliferated chondrocytes, disappearing distinction between AF and NP and damaged endplates, when compared to (c) the relative normal IVD at the adjacent level. In particular, curcumin administered group (b, right column) exhibited a stronger purplish staining in the inner AF region and a more intense red staining in the outer AF area, suggesting an active regeneration process of newly formed proteoglycan and collagen. Scale bar $=100 \mu \mathrm{m}$. Five mice were used in each group. 
a mouse model of lumbar radiculopathy caused by disc herniation. Curcumin's actions against neuroinflammation, oxidative stress and nociceptive factors may synergistically contribute to this beneficial effect. Without doubt, our data provide pre-clinical evidence supporting curcumin as a clinical treatment for painful IVD.

Since the painful IVD degeneration involves the complex cross-talking between herniated disc and nerve root within close proximity, the beneficial effects of curcumin to both would be highly preferred to deliver simultaneous therapeutic effects. However, published results regarding the role of curcumin in the context of disc degeneration are controversial. Ma T (2005) has shown that, in rats, curcumin could inhibit the activation of NF- $\kappa \mathrm{B}$, by inhibiting the translocation of NF- $\mathrm{KB}-\mathrm{p} 65$, and reduce the release of inflammatory factors to decelerate the process of lumbar intervertebral disc degeneration. Klawitter et al. (2012) indicated that, in human disc cells, curcumin's action did not involve NF- $\kappa$ B, but down-regulated TLR2 expression and inhibited the MAP kinase JNK, while activating p38 and ERK. A more recent study revealed that TLR2 or NF- $\kappa$ B inhibition might both attenuate chronic pain and retard disc degeneration (Krock et al. 2016). In our study, histological staining suggested that systemic administrations of curcumin had a regenerative effect on herniated disc, as seen by newly formed collagen and proteoglycan extracellular matrix proteins (Fig. 6). Although curcumin's effect on herniated disc was not the focus of the current study, this is the first observation of the in vivo regeneration effect of systemically administered curcumin in a mouse disc herniation model.

Given the proven therapeutic effect and reliable safety profile of curcumin, concerns still exist regarding its poor bioavailability, fast elimination (Margină et al., 2015) and time points for curcumin administration in clinical setting. Most studies were performed on cancer patients, so that the long-term effect of curcumin administration will have to be assessed in patients with degenerative disc disease. In our proof of concept study, curcumin injection started immediately after surgery. However, this does not indicate that curcumin only acts at early stage of induced radiculopathy and a more comprehensive study plan (e.g. pre-, intra- and postsurgery injection) should be investigated in future. In addition, the intraperitoneal injection of curcumin had to be performed every other day to maintain the desired analgesic effect in mice, since curcumin underwent rapid plasma clearance and conjugation. Since it bears little toxicity, frequent administration of this agent is feasible. Meanwhile, researchers have been developing new polymeric formulations and chemical modifications to increase systemic bioavailability. For example, curcumin was chemically modified and conjugated to a thermoresponsive elastin-like polypeptide (ELP) as an injectable depot for sustained, local delivery of curcumin to treat neuroinflammation (Sinclair et al., 2013). A curcuminloaded polymeric microsphere was also developed as an interventional strategy to overcome apoptosis associated with pancreatic islets transplantation (Pathak et al., 2016). Nanocarrier systems (hydrogels, polymeric nanoparticles, liposomes and self-assembling nanofibres) might be promising strategies to improve drug bioavailability, prolong systemic circulation and, possibly, incorporate other therapeutic agents to realise a multi-targeted synergistic effect (Joshi et al., 2013).

In summary, we report that, in a mouse model of lumbar radiculopathy secondary to disc herniation, systemic administration of curcumin can be a potent treatment, attenuating TNF- $\alpha$-induced neuroinflammation, excessive ROS production and nociceptive factors. Our study provides fundamental pre-clinical evidence to support the application of this non-toxic naturally occurring pleiotropic

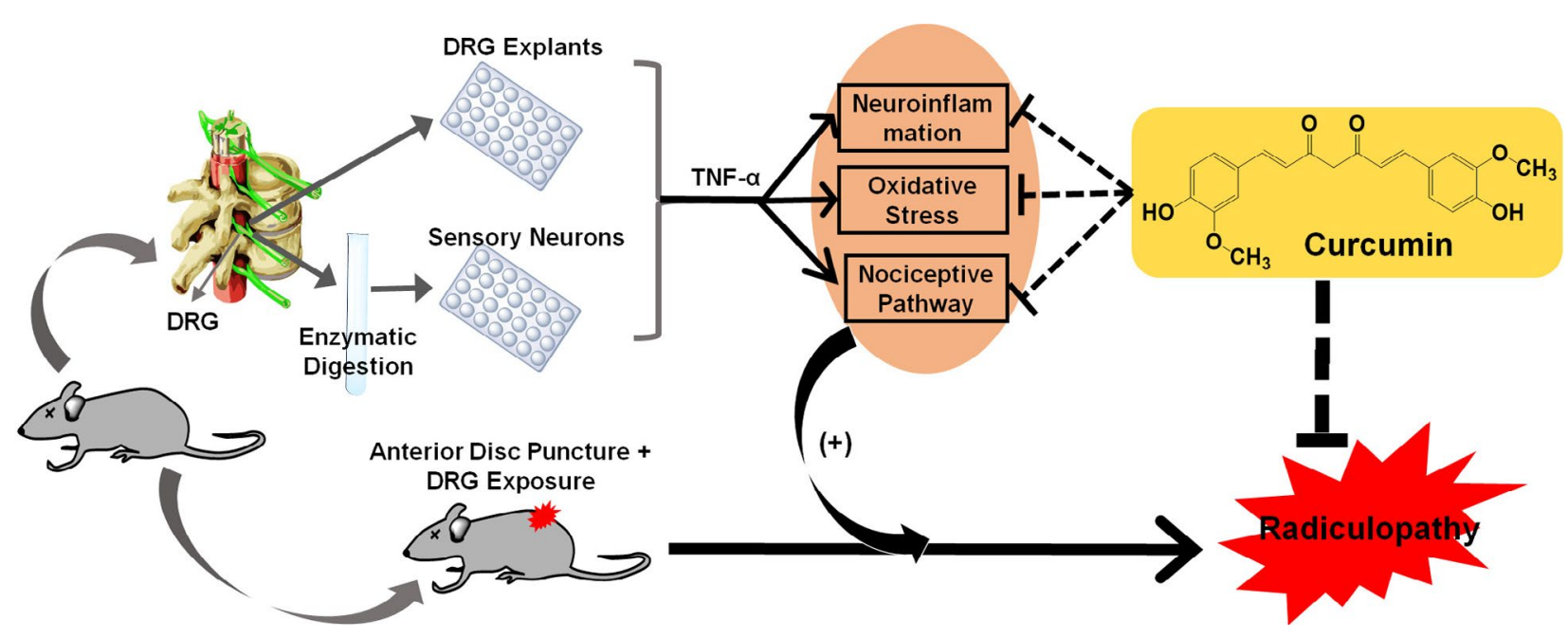

Fig. 7. Schematic hypothesis of the current study in exploring curcumin's therapeutic potential to combat radiculopathy secondary to disc herniation: 1) In vitro pleiotropic functions of curcumin via via attenuating attenuation of TNF- $\alpha$-induced neuroinflammation, ROS production and nociceptive factors in isolated mouse DRG and primary neurons; 2) In vivo analgesic effect of systemically administered curcumin in a mouse model of lumbar radiculopathy secondary to disc herniation. 
molecule in lumbar radiculopathy and discogenic low back pain.

\section{Acknowledgements}

We are grateful for the financial support partially received from NIH NIAMS R01AR064792 and North American Spine Society.

\section{References}

Andersson GBJ (1999) Epidemiological features of chronic low-back pain. Lancet 354: 581-585.

Arulselvan P, Fard MT, Tan WS, Gothai S, Fakurazi S, Norhaizan ME, Kumar SS (2016) Role of antioxidants and natural products in inflammation. Oxid Med Cell Longev 2016: 5276130.

Belavý DL, Albracht K, Bruggemann G-P, Vergroesen P-PA, van Dieën JH (2016) Can exercise positively influence the intervertebral disc?. Sports Med 46: 473-485.

Bhatia A, Flamer D, Shah P, Cohen SP (2016) Transforaminal epidural steroid injections for treating lumbosacral radicular pain from herniated intervertebral discs: a systematic review and meta-analysis. Anesth Analg 122: 857-870.

Biddie SC, Conway-Campbell BL, Lightman SL (2012) Dynamic regulation of glucocorticoid signalling in health and disease. Rheumatology (Oxford) 51: 403-412.

Bonin RP, Bories C, De Koninck Y (2014) A simplified up-down method (SUDO) for measuring mechanical nociception in rodents using von Frey filaments. Mol Pain 10: 26 .

Brenna JT, Akomo P, Bahwere P, Berkley JA, Calder PC, Jones KD, Liu L, Manary M, Trehan I, Briend A (2015) Balancing omega- 6 and omega- 3 fatty acids in ready-to-use therapeutic foods (RUTF). BMC Med 13: 117.

Cao H, Zheng J-w, Li J-j, Meng B, Li J, Ge R-s (2014) Effects of curcumin on pain threshold and on the expression of nuclear factor $\kappa \mathrm{B}$ and $\mathrm{CX} 3 \mathrm{C}$ receptor 1 after sciatic nerve chronic constrictive injury in rats. Chin J Integr Med 20: $850-856$.

Chainani-Wu N (2003) Safety and anti-inflammatory activity of curcumin: a component of tumeric (curcuma longa). J Altern Complement Med 9: 161-168.

Feldmann M, Maini RN (2003) TNF defined as a therapeutic target for rheumatoid arthritis and other autoimmune diseases. Nat Med 9: 1245-1250.

Frearson J, Wyatt P (2010) Drug discovery in academiathe third way?. Expert Opin Drug Discov 5: 909-919.

Gruber HE, Ingram J, Jr ENH (2002) An improved staining method for intervertebral disc tissue. Biotech Histochem 77: 81-83.

Guterl CC, See EY, Blanquer SBG, Pandit A, Ferguson SJ, Benneker LM, Grijpma DW, Sakai D, Eglin D, Alini M, Iatridis JC, Grad S (2013) Challenges and strategies in the repair of ruptured annulus fibrosus. Eur Cells Mater 25: 1-21.

Hoy D, March L, Brooks P, Blyth F, Woolf A, Bain C, Williams G, Smith E, Vos T, Barendregt J, Murray C,
Burstein R, Buchbinder R (2014) The global burden of low back pain: estimates from the Global Burden of Disease 2010 study. Ann Rheum Dis 6: 968-974.

Isyar M, Bilir B, Yilmaz I, Cakmak S, Sirin DY, Guzelant AY, Mahirogullari M (2015) Are biological agents toxic to human chondrocytes and osteocytes?. J Orthop Surg Res 10: 118.

Jeon Y, Kim C-E, Jung D, Kwak K, Park S, Lim D, Kim S, Baek W (2013) Curcumin could prevent the development of chronic neuropathic pain in rats with peripheral nerve injury. Curr Ther Res Clin Exp 74: 1-4.

Jin L, Feng G, Reames DL, Shimer AL, Shen FH, Li X (2013) The effects of simulated microgravity on intervertebral disc degeneration. Spine J 13: 235-242.

Jo YY, Lee JY, Park C-K (2016) Resolvin E1 inhibits substance P-induced potentiation of TRPV1 in primary sensory neurons. Mediators Inflamm 2016: 5259321.

Joshi RP, Negi G, Kumar A, Pawar YB, Munjal B, Bansal AK, Sharma SS (2013) SNEDDS curcumin formulation leads to enhanced protection from pain and functional deficits associated with diabetic neuropathy: an insight into its mechanism for neuroprotection. Nanomedicine: 9: 776-785.

JS J (2009) Anti-inflammatory properties of curcumin, a major constituent of curcuma longa: a review of preclinical and clinical research. Altern Med Rev 14: 141-153.

Kepler CK, Ponnappan RK, Tannoury CA, Risbud MV, Anderson DG (2013) The molecular basis of intervertebral disc degeneration. Spine J 13: 318-330.

Khatri DK, Juvekar AR (2016) Neuroprotective effect of curcumin as evinced by abrogation of rotenone-induced motor deficits, oxidative and mitochondrial dysfunctions in mouse model of Parkinson's disease. Pharmacol Biochem Behav 150-151: 39-47.

Klawitter M, Quero L, Klasen J, Gloess AN, Klopprogge B, Hausmann O, Boos N, Wuertz K (2012) Curcuma DMSO extracts and curcumin exhibit an anti-inflammatory and anti-catabolic effect on human intervertebral disc cells, possibly by influencing TLR2 expression and JNK activity. J Inflamm (London) 9: 29-29.

Krock E, Rosenzweig DH, Chabot-Doré A-J, Jarzem P, Weber MH, Ouellet JA, Stone LS, Haglund L (2014) Painful, degenerating intervertebral discs up-regulate neurite sprouting and CGRP through nociceptive factors. J Cell Mol Med 18: 1213-1225.

Krock E, Currie JB, Weber MH, Quellet JA, Stone LS, Rosenzweig DH, Haglund L (2016) Nerve growth factor is regulated by toll-like receptor 2 in human intervertebral disc. J Biol. Chem 291: 3541-3551.

Kübra Elçioğlu H, Kabasakal L, Tufan F, Elçioğlu ÖH, Solakoglu S, Kotil T, Karan MA (2015) Effects of systemic thalidomide and intracerebroventricular etanercept and infliximab administration in a streptozotocin induced dementia model in rats. Acta Histochem 117: 176-181.

Kunnumakkara AB, Anand P, Aggarwal BB (2008) Curcumin inhibits proliferation, invasion, angiogenesis and metastasis of different cancers through interaction with multiple cell signaling proteins. Cancer Lett 269: 199-225.

La Binch A, Cole AA, Breakwell LM, Michael ALR, Chiverton N, Cross AK, Le Maitre CL (2014) Expression and regulation of neurotrophic and angiogenic factors 
during human intervertebral disc degeneration. Arthritis Res Ther 16: 416.

Leung L, Cahill CM (2010) TNF- $\alpha$ and neuropathic pain - a review. J Neuroinflammation 7: 27-27.

Liu Q, Jin L, Mahon BH, Chordia MD, Shen FH, Li X (2013) A novel treatment of neuroinflammation against low back pain by soluble fullerol nanoparticles. Spine (Phila Pa 1976) 38: 1443-1451.

Lories RJ, de Vlam K (2014) Tumour necrosis factor inhibitors in the treatment of psoriatic arthritis: a view on effectiveness, clinical practice and toxicity. Expert Opin Biol Ther 14: 1825-1836.

Ma T GC, Zhao X, Wu T, Sun SX, Jin QH (2015) The effect of curcumin on NF- $\kappa$ B expression in rat with lumbar intervertebral disc degeneration. Eur Rev Med Pharmacol Sci 19: 1305-1314.

Malin SA, Davis BM, Molliver DC (2007) Production of dissociated sensory neuron cultures and considerations for their use in studying neuronal function and plasticity. Nat Protoc 2: 152-160.

Margină D, Ilie M, Grădinaru D, Androutsopoulos VP, Kouretas D, Tsatsakis AM (2015) Natural products friends or foes?. Toxicol Lett 236: 154-167.

Martinov T, Mack M, Sykes A, Chatterjea D (2013) Measuring changes in tactile sensitivity in the hind paw of mice using an electronic von Frey apparatus. J Vis Exp 82: e51212.

Mattei RA, Dalmarco EM, Fröde TS (2015) Etanercept administration prevents the inflammatory response induced by carrageenan in the murine air pouch model. Naunyn Schmiedebergs Arch Pharmacol 388: 1247-1257.

McDermott AM, Toelle TR, Rowbotham DJ, Schaefer CP, Dukes EM (2006) The burden of neuropathic pain: results from a cross-sectional survey. Eur J Pain 10: $127-$ 127.

Meng B, Shen L-1, Shi X-t, Gong Y-s, Fan X-f, Li J, Cao H (2015) Effects of curcumin on TTX-R sodium currents of dorsal root ganglion neurons in type 2 diabetic rats with diabetic neuropathic pain. Neurosci Lett 605: 59-64.

Noorafshan A, Omidi A, Karbalay-Doust S (2011a) Curcumin protects the dorsal root ganglion and sciatic nerve after crush in rat. Pathol Res Pract 207: 577-582.

Noorafshan A, Omidi A, Karbalay-Doust S, Aliabadi E, Dehghani F (2011b) Effects of curcumin on the dorsal root ganglion structure and functional recovery after sciatic nerve crush in rat. Micron 42: 449-455.

Park C-K, Lü N, Xu Z-Z, Liu T, Serhan CN, Ji R-R (2011) Resolving TRPV1 and TNF- $\alpha$ mediated spinal cord synaptic plasticity and inflammatory pain with neuroprotectin D1. The J Neurosci 31: 15072-15085.

Pathak S, Regmi S, Gupta B, Poudel BK, Pham TT, Kim J-R, Park P-H, Yong CS, Kim JO, Bae YK, Kim SK, Jeong J-H (2016) Hybrid congregation of islet single cells and curcumin-loaded polymeric microspheres as an interventional strategy to overcome apoptosis associated with pancreatic islets transplantation. ACS Appl Mater Interfaces 8: 25702-25713.

Purmessur D, Freemont AJ, Hoyland JA (2008) Expression and regulation of neurotrophins in the nondegenerate and degenerate human intervertebral disc. Arthritis Res Ther 10: R99.

Rahimifard M, Maqbool F, MoeiniNodeh S, Niaz K, Abdollahi M, Braidy N, Nabavi SM, Nabavi SF (2017) Targeting the TLR4 signaling pathway by polyphenols: a novel therapeutic strategy for neuroinflammation. Ageing Res Rev. 36:11-19.

Ramsden CE, Faurot KR, Zamora D, Palsson OS, MacIntosh BA, Gaylord S, Taha AY, Rapoport SI, Hibbeln JR, Davis JM, Mann JD (2015) Targeted alterations in dietary n-3 and n-6 fatty acids improve life functioning and reduce psychological distress among chronic headache patients: secondary analysis of a randomized trial. Pain 156: $587-596$.

Richardson SM, Doyle P, Minogue BM, Gnanalingham K, Hoyland JA (2009) Increased expression of matrix metalloproteinase-10, nerve growth factor and substance $\mathrm{P}$ in the painful degenerate intervertebral disc. Arthritis Res Ther 11: R126.

Ringer C, Tune S, Bertoune MA, Schwarzbach H, Tsujikawa K, Weihe E, Schütz B (2016) Disruption of calcitonin gene-related peptide signaling accelerates muscle denervation and dampens cytotoxic neuroinflammation in SOD1 mutant mice. Cell Mol Life Scie 74: 339-358.

Rohanizadeh R, Deng Y, Verron E (2016) Therapeutic actions of curcumin in bone disorders. Bonekey Rep 5: 793.

Sainoh T, Orita S, Miyagi M, Sakuma Y, Yamauchi K, Suzuki M, Kubota G, Oikawa Y, Inage K, Sato J, Fujimoto K, Shiga Y, Inoue G, Aoki Y, Takahashi K, Ohtori S (2015) Interleukin-6 and interleukin-6 receptor expression, localization, and involvement in pain-sensing neuron activation in a mouse intervertebral disc injury model. $\mathrm{J}$ Orthop Res 33: 1508-1514.

Shehzad A, Ha T, Subhan F, Lee YS (2011) New mechanisms and the anti-inflammatory role of curcumin in obesity and obesity-related metabolic diseases. Eur J Nutr 50: 151-161.

Sinclair SM, Bhattacharyya J, McDaniel JR, Gooden DM, Gopalaswamy R, Chilkoti A, Setton LA (2013) A genetically engineered thermally responsive sustained release curcumin depot to treat neuroinflammation. J Control Release 171: 38-47.

Walter BA, Torre OM, Laudier D, Naidich TP, Hecht AC, Iatridis JC (2015) Form and function of the intervertebral disc in health and disease: a morphological and stain comparison study. J Anat 227: 707-716.

Xiao L, Ding M, Saadoon O, Vess E, Fernandez A, Zhao P, Jin L, Li X (2016) A novel culture platform for fast proliferation of human annulus fibrosus cells. Cell Tissue Res 367: 1-12.

Zammataro M, Sortino MA, Parenti C, Gereau RW, Chiechio S (2014) HDAC and HAT inhibitors differently affect analgesia mediated by group II metabotropic glutamate receptors. Mol Pain 10: 68 .

Zhao J, Luo D, Liang Z, Lao L, Rong J (2016) Plant Natural Product Puerarin Ameliorates depressive behaviors and chronic pain in mice with spared nerve injury (SNI). Mol Neurobiol 54:2801-2812 
Zhou H, Beevers CS, Huang S (2011) Targets of curcumin. Current Drug Targets 12: 332-347.

\section{Discussion with Reviewers}

Karin Wuertz-Kozak: The stability of curcumin has been demonstrated to be $\mathrm{pH}$-dependent. Could the authors speculate on how an ideal delivery system might hence look like?

Authors: As we discussed, future development of various nanocarrier systems to improve the overall pharmacological profile of curcumin (such as bioavailability, retention and $\mathrm{pH}$-sensitivity) might be speculated. Some examples of nanocarrier might include hydrogels, polymeric nanoparticles, liposomes and self-assembling nanofibers, which have all been reported to enhance the therapeutic efficiency of anticancer drugs by facilitating local drug accumulation, developing drug bioavailability and prolonging systemic circulation. In addition, their capability of incorporating two or more therapeutic agents into one nanocarrier is very appealing. In terms of treating lumbar radiculopathy, we may adopt a similar concept by incorporating the anti-inflammatory curcumin with another therapeutic agent (e.g. link $\mathrm{N}$ peptide for disc regeneration) into one nanocarrier system. For targeted delivery, subsequent modification on the nano-surface with a targeting moiety (such as a peptide) may be carried out, given the mature chemistry protocols developed in biomaterial science.

Li Zhen: Does curcumin target the upstream or downstream pathway of induced radiculopathy secondary to disc herniation? What are the indications for applying such drug in clinics?

Authors: We don't know whether curcumin targets the upstream or downstream of the radiculopathy. Based on the literatures and our study, curcumin has anti-oxidative and anti-inflammatory effects, which may possess impacts on the initial stage of the disease, as inflammation occurs shortly after disc herniation. However, as disc herniation is a chronic disease with continuous inflammatory responses and nerve irritation, curcumin may also antagonise such inflammation later on.

In our opinion, there might be two possible routes for applying curcumin in the therapeutic context of lumbar radiculopathy: directly incorporate curcumin as a supplemental prescription and, meanwhile, further develop a new formulation such as a nanocarrier system to incorporate curcumin along with other therapeutic agents for either local or systemic delivery.

Editor's note: The Scientific Editor responsible for this paper was Mauro Alini. 